\title{
Раннепротерозойские кааламский и велимякский магматические комплексы Северного Приладожья: источники и эволюция магм
}

\author{
Анисимов Р.Л. ${ }^{1}$, Кириллова П.А. ${ }^{1}$, Петракова М.Е. ${ }^{1}$, Балтыбаев Ш.К. ${ }^{1,2}$ \\ ${ }^{1}$ Институт геологии и геохронологии докембрия РАН, Санкт-Петербург, romjulleoanis@mail.ru \\ ${ }^{2}$ Санкт-Петербургский государственный университет, Санкт-Петербург, shauket@mail.ru
}

Аннотация. Раннепротерозойские интрузии Кааламо и Велимяки имеют схожий U-Pb возраст ( 1.88 млрд лет). Породы Велимяки содержат больше щелочей и характеризуются субщелочным эволюционным трендом, тогда как для Кааламо характерен известково-щелочной тренд. Определены составы, которые могли бы отвечать составу родоначальной магмы. Родоначальная магма Велимяки отличалась повышенным отношением $\left(\mathrm{Na}_{2} \mathrm{O}+\mathrm{K}_{2} \mathrm{O}\right) / \mathrm{SiO}_{2}$. Оба массива могли сформироваться из одного источника, если в ходе эволюции велимякская магма перетерпела контаминацию коровым веществом.

Ключевые слова: Кааламо, Велимяки, MCS, габбро, интрузия, моделирование.

\section{Kaalamo and velimyaky early-proterozoic magmatic complexes of the Northern Ladoga area: sources and evolution of magmas}

\author{
Anisimov R.L. ', Kirillova P.A. ${ }^{1}$, Petrakova M.E. ${ }^{1}$, Baltybaev S.K. ${ }^{1,2}$ \\ ${ }^{1}$ Institute of Precambrian geology and geochronology RAS, St.-Petersburg, Russia, romjulleoanis@mail.ru \\ ${ }^{2}$ Saint-Petersburg State University,St.-Petersburg, Russia, shauket@mail.ru
}

\begin{abstract}
Early-proterozoic Kaalamo and Velimyaky intrusions have a similar absolute age ( $\approx 1.88 \mathrm{Ga})$. Rocks of the Velimyaky contain a significant amount of alkali metals and form a subalkaline evolution trend. The compositions have been determined that could correspond to the composition of the parental magma. Parental magma of Velimyaky has had increased $(\mathrm{Na} 2 \mathrm{O}+\mathrm{K} 2 \mathrm{O}) / \mathrm{SiO} 2$ ratio. Both massifs could have formed from the same source if magma of Velimyaky was contaminated with material from the crust.
\end{abstract}

Key words: Kaalamo, Velimyaky, MCS, gabbro, intrusion, modeling.

\section{Введение}

Кааламский и велимякский магматические комплексы находятся в пределах Раахе-Ладожской зоны сочленения архейского Карельского кратона и протерозойской Свекофеннской складчатой области. Эти комплексы представляют собой серию интрузий, наиболее крупные из которых- Кааламский и Велимякский (рис. 1).

Изучение этих массивов началось еще два столетия назад, что связано с их рудоносностью. Но, несмотря на длительную историю изучения и полученные подробные сведений о составах пород этих двух комплексов, пока только констатируется тот факт, что эволюционные тренды их различаются на два типа: субщелочной у велимякского комплекса и известково-щелочной - у кааламского (рис. 2 а). Это различие находит отражение на минеральном уровне: в породах массива Велимяки наблюдается калиевый полевой шпат, который в средних породах может преобладать над плагиоклазом («мангериты» по Г. М. Саранчиной).

Исследователи расходились во мнении о причине повышенной щелочности габброидов велимякского комплекса - одни считали, что это является особенностью состава первичных магм (Саранчина, 1948), а другие (Алексеев, Кулешевич, 2017), полагали , что при наложенных процессах возникает калишпатовый парагенезис и породы приобретают субщелочной тренд.

Мы попытались получить ответы на вопрос о специализации магм и количественно оценить возможные механизмы дифференциации первичных расплавов при чистой фракционной кристаллизации (FC) и фракционной кристаллизации с сопутствующей ассимиляцией боковых пород (AFC). 

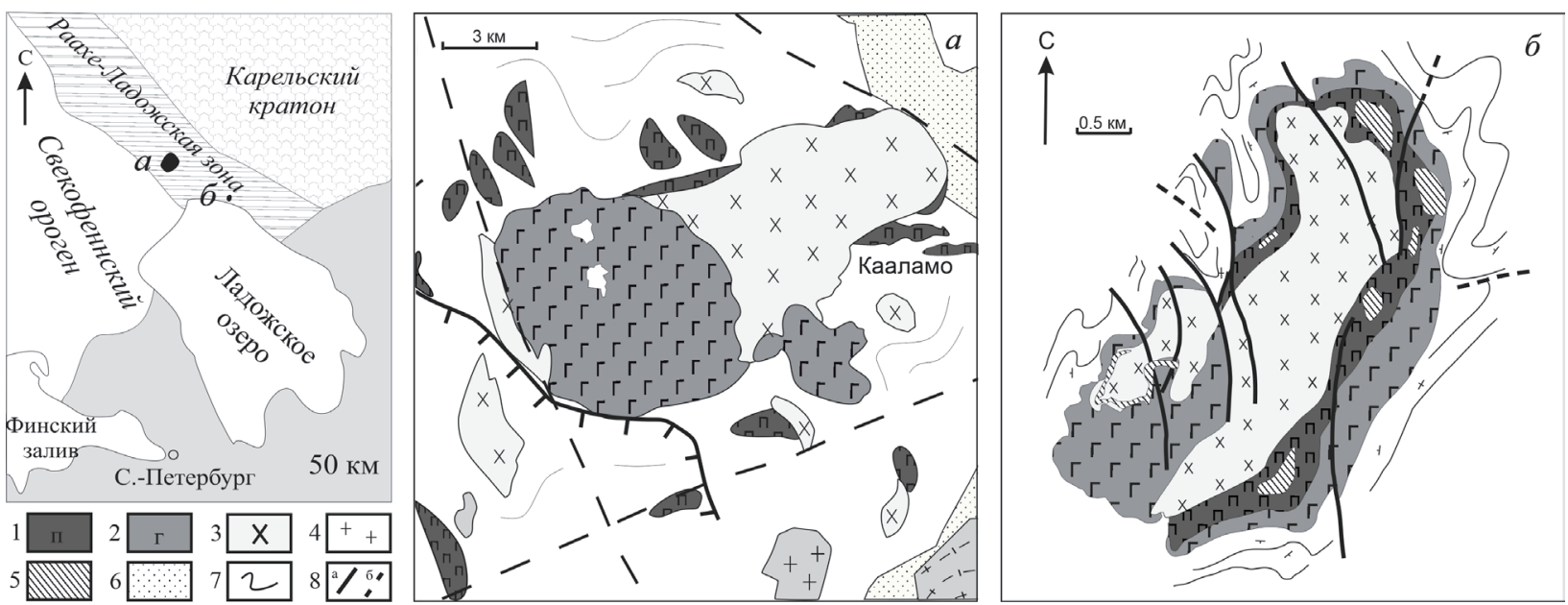

Рис. 1. Схематические карты Кааламского $(a)$ и Велимякского (б) массивов (Ладожская протерозойская..., 2020) с дополнениями. 1 - преимущественно пироксениты, 2 - габбро, габбронориты, габбродиориты, 3 - диориты, габбродиориты, 4 - граниты, 5 - рудные пиросениты, 6 - породы сортавальской серии, 7 - породы ладожской серии, 8 - разломы: $a$ - видимые, $\sigma$ - предполагаемые.

Fig. 1. Schematized geological maps of Kaalamo (a) and Velimyaky (б) massifs (Proterozoic Ladoga... 2020) with corrections. 1 - pyroxenites predominantly, 2 - gabbro, gabbro-norites, gabbro-diorites, 3 - diorites, gabbro-diorites, 4 - granites, 5 - ore pyroxenites, 6 - rocks of Sortavala series, 7 - rocks of Ladoga series, 8 - faults: $a$-visible, 6 -proposed.
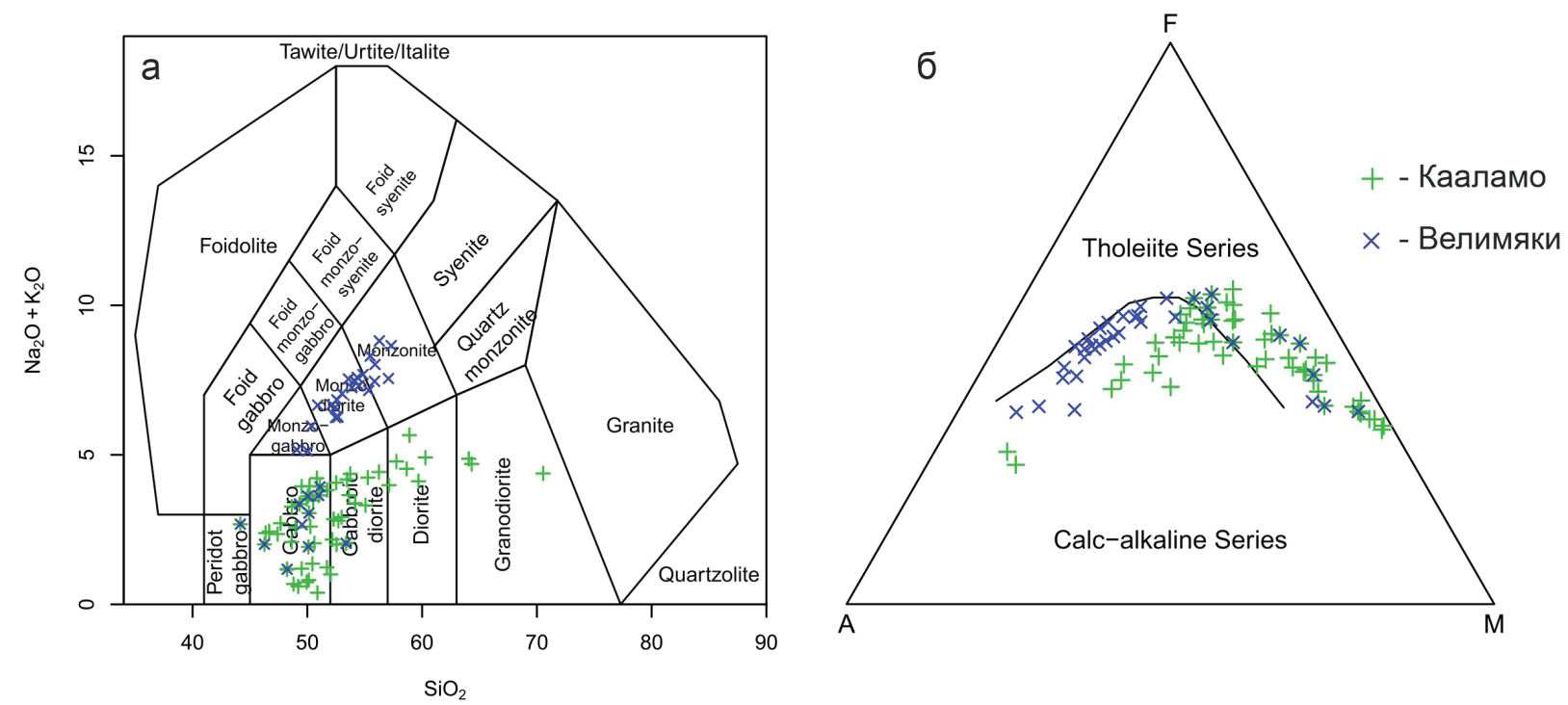

Рис. 2. Классификационные диаграммы для пород кааламского и велимякского комплексов: a - TAS (Middlemost, 1994), б - AFM (Irvin, Baragar, 1971). Авторские и опубликованные данные (Ладожская протерозойская..., 2020).

Fig. 2. Classification diagrams for каalamo and velimyaky complexes: a - TAS (Middlemost, 1994), 6 - AFM (Irvin, Baragar, 1971). The author's and published data were used (Proterozoic Ladoga... 2020).

\section{Методика исследования}

Для моделирования эволюции расплавов в процессе образования Велимякской и Кааламской интрузий нами использовалось приложение Magma Chamber Simulator (MCS) (Bohrson et al., 2014; https://mcs.geol.ucsb.edu/). MCS основан на базе программ семейства MELTS (http://melts.ofmresearch.org/) и позволяет производить термодинамическое моделирование FC, AFC, а также учитывать смешение с добавочными порциями расплава (RFC или RAFC). Для настоящего исследования 
нами выбран вариант Rhyolite-MELTS 1.1.0 (Gualda et al., 2012; Ghiorso and Gualda, 2015). Были использованы 93 XRF-анализа пород Кааламо и Велимяки.

\section{Составы пород, петрохимия и геохимия}

На диаграмме TAS составы кааламских пород варьируют от габбро до гранодиоритов, а велимякских - от габбро до монцогаббро и монцонитов (рис. 2 а). Отношение $\mathrm{Na}_{2}$ Осред./ $/ \mathrm{K}_{2} \mathrm{Ocpeд.} \mathrm{в}$ породах Кааламо составляет 2.36; а в породах Велимяки - 1.46 (для Кааламо - среднее из 58 анализов, для Велимяки - из 36 анализов). Это означает, что доля $\mathrm{Na}_{2} \mathrm{O}$ преобладает над $\mathrm{K}_{2} \mathrm{O}$ как в Кааламо, так и в Велимяки, но в Велимяки это преобладание слабее. На AFM-диаграмме оба интрузива образуют схожие переходные тренды от толеитового ряда к известково-щелочному с ростом $\mathrm{SiO}_{2}$ (рис. 2 б).

Породы Кааламо и Велимяки массивов имеют схожие спектры распределения REE: значительное обогащение LREE относительно HREE, отсутствие значительных Eu-аномалий. Исключение составляют диориты Кааламо, для них характерны более низкие концентрации REE, при этом степень фракционирования их сильнее и наблюдаются также большие положительные Еu-аномалии (Кириллова и др., 2020).

\section{Моделирование родоначальных расплавов Кааламо и Велимяки}

Для моделирования эволюции магматических систем необходимо знать состав родоначального расплава. Для того, чтобы его определить существуют разные подходы (расчет среднего состава интрузива, использование составов автолитов, малых дайковых тел, не претерпевших дифференциацию и пр.). Мы смоделировали фракционную кристаллизацию, принимая за гипотетический родоначальный расплав все имеющиеся у нас составы пород этих массивов (93 анализа) при начальных параметрах: давление 4 кбар, что отвечает оценкам по минеральным геобарометрам окружающих пород (Геология..., 2000), содержание воды в расплаве 1-6 вес.\%, кислородный буфер QFM. Тренды изменения составов остаточных расплавов в ходе FC наносились на TAS-диаграмму. Результаты показали, что подавляющее большинство составов пород Велимяки образовало типичный для Велимякского массива субщелочной тренд. Для Кааламо оказалось, что примерно половина анализов порождает типичный для него известково-щелочной тренд, а другая половина - субщелочной (рис. 3).

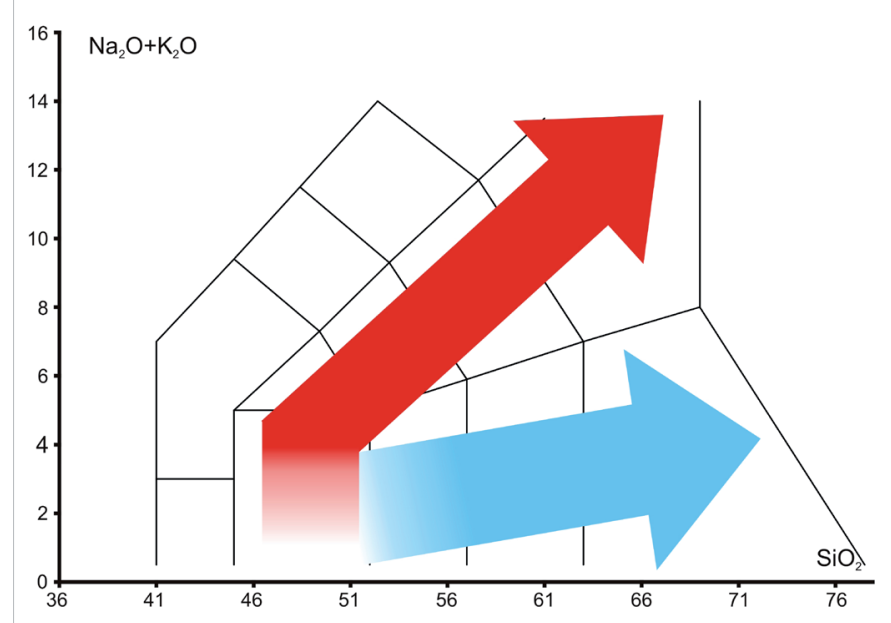

Рис. 3. Типичные тренды составов остаточных расплавов для Кааламской и Велимякской интрузий.

Fig.3. Typical compositional trends of residual melts of the Kaalamo and Velimyaky intrusions.

Мы рассмотрели возможные факторы, которые могли привести к появлению двух типов трендов. Как видно на рисунке 4, увеличение общего давления приводит к выполаживанию тренда, а увеличение содержания воды в расплаве делает тренд более известково-щелочным. В целом, можно отметить, что влияние давления и содержания воды на поведение тренда незначительно, не может привести к появлению двух типов трендов. Была рассмотрена также взаимосвязь между составом породы и типом тренда, который она образует. Для этого были выделены составы пород, отве- 


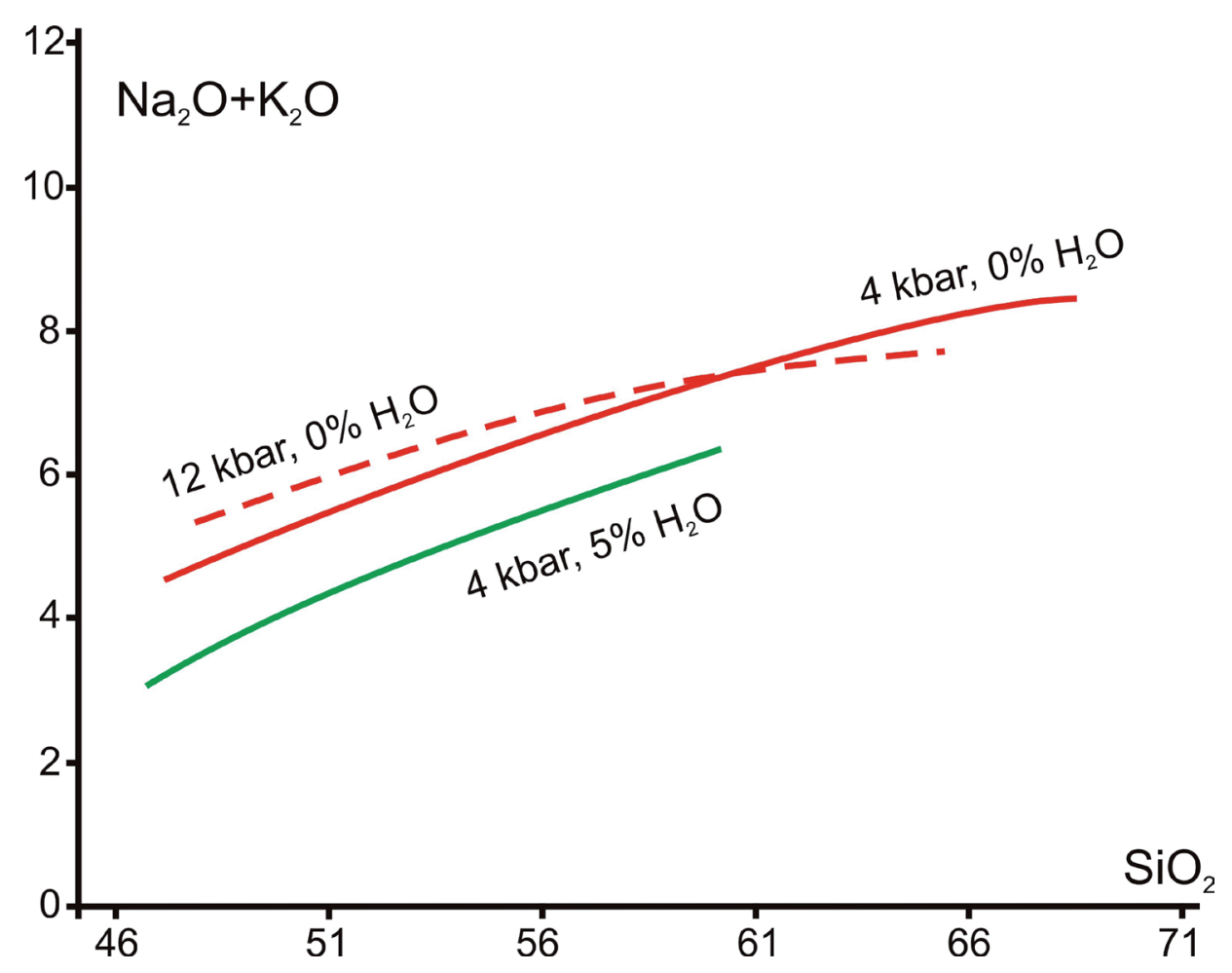

Рис. 4. Поведение трендов составов остаточных расплавов при изменении общего давления и содержания воды в расплаве.

Fig.4. Behavior of compositional trends of residual melts depending on changes in total pressure and water content in the melt.

чающие наименее дифференцированным разностям (габброиды) как наиболее вероятные родоначальные расплавы для массивов.

Габброиды массива Кааламо четко разделились на две группы - составы с известковощелочным и с субщелочным типом тренда. Эти две группы занимают закономерные области на большинстве диаграмм (рис. 5). По полученным данным выделена сравнительно узкая область составов, которые порождают известково-щелочной тренд эволюции магматической системы, характерный для Кааламо. Эти составы объединяет пониженное отношение $\left(\mathrm{Na}_{2} \mathrm{O}+\mathrm{K}_{2} \mathrm{O}\right) / \mathrm{SiO}_{2}$.

Каким мог быть родоначальный расплав для Велимякской интрузии? Это мог быть расплав, отличающийся повышенным отношением $\left(\mathrm{Na}_{2} \mathrm{O}+\mathrm{K}_{2} \mathrm{O}\right) / \mathrm{SiO}_{2}$.

Мы предполагаем, что это мог быть и сам родоначальный расплав Кааламо, претерпевший контаминацию вмещающими породами. Однако, эта контаминация должна происходить на достаточно большой глубине, потому что, на уровне магматической камеры Велимяки потребуется значительное время для прогрева вмещающих пород до состояния плавления. Это приведет к тому, что тренд эволюции остаточного расплава начнет переходить в субщелочную область уже на поздних этапах эволюции магматической системы, что не отвечает наблюдаемому в Велимякском массиве. При проверке модели ассимиляции для всех гипотетических родоначальных расплавов «кааламского типа» на глубине, соответствующей давлению 8 кбар (в качестве вмещающей породы был взят средний состав гранито-гнейсов Кирьяволахтинского купола (Лобач-Жученко и др., 1974)) были получены субщелочные тренды, подобные трендам Велимяки.

\section{Выводы}

Составы, которые могли бы отвечать родоначальному расплаву Кааламо объединяет пониженное отношение суммы щелочей при одинаковой кремнекислотности.

Родоначальный расплав Велимякской интрузии мог быть схожим с родоначальным расплавом Кааламо, но отличаться повышенным отношением $\left(\mathrm{Na}_{2} \mathrm{O}+\mathrm{K}_{2} \mathrm{O}\right) / \mathrm{SiO}_{2}$. 

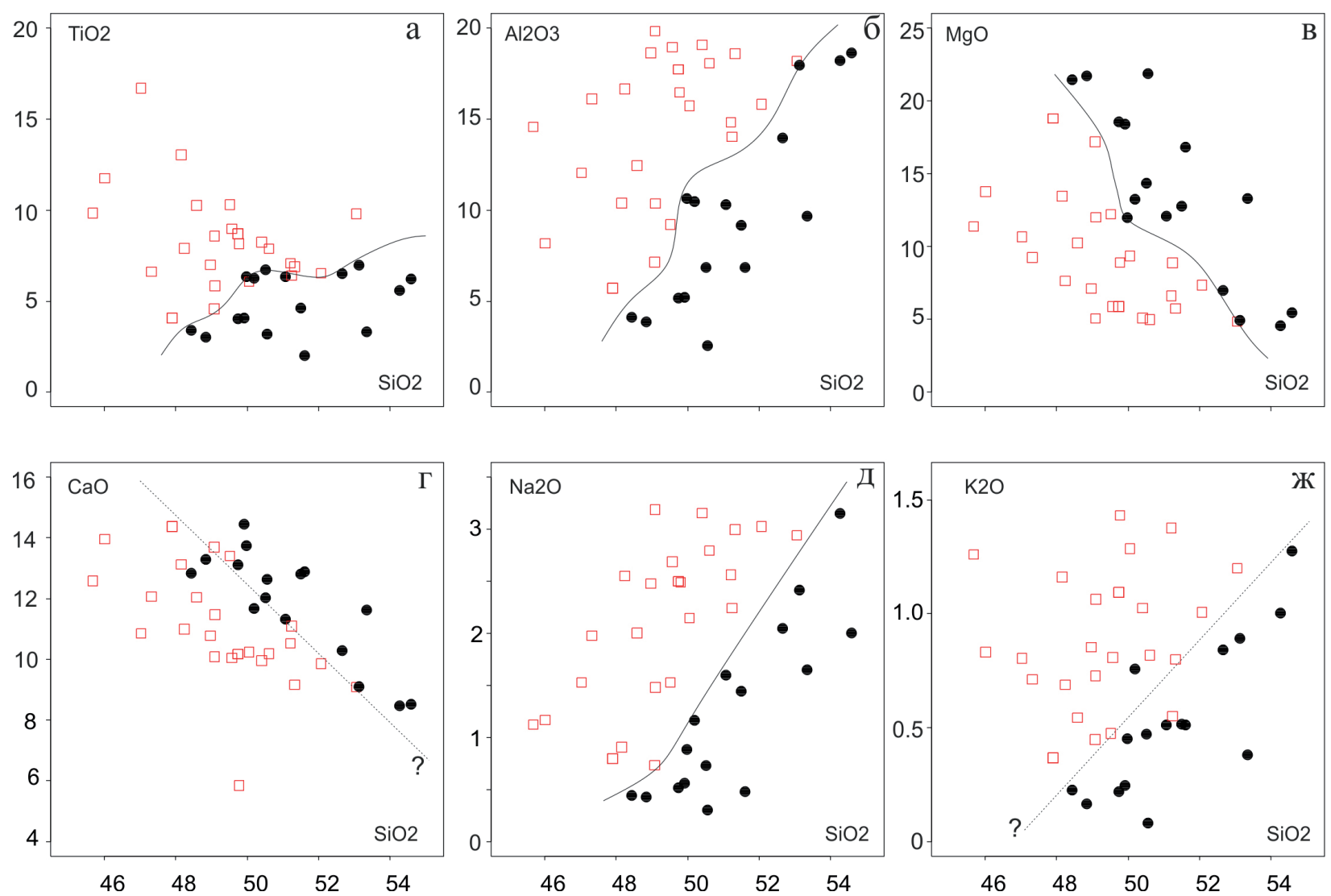

Рис. 5. Диаграммы оксид-SiO 2 для габброидов Кааламо. Квадраты - составы, порождающие субщелочные тренды эволюции остаточных расплавов; круги - составы, порождающие известково-щелочные тренды.

Fig. 5. Diagrams oxid- $\mathrm{SiO}_{2}$ for gabbroids of Kaalamo. Squares are compositions with subalkaline compositional trends of residual melts; circles are compositions with calc-alkaline compositional trends.

Оба массива могли сформироваться из одного источника, если в ходе эволюции велимякская магма претерпела контаминацию коровым веществом.

Работа выполнена в рамках темы НИР № FMUW-2019-0013.

\section{Литература}

1. Алексеев И.А., Кулешевич Л.В. Благороднометалльная минерализация массива Вялимяки (Северное Приладожье, Карелия) // Труды КарНЦ РАН. 2017. сер. Геология докембрия. № 2. С. 60-72. DOI: $10.17076 /$ geo 115.

2. Геология и петрология свекофеннид Приладожья (ред. В.А. Глебовицкий). СПб. Изд-во: СПбГУ. 2000. $200 \mathrm{c}$.

3. К Кириллова П.А., Анисимов Р.Л., Галанкина О.Л., Балтыбаев Ш.К. Геохимические особенности раннепротерозойских полифазных интрузийгабброидов Северного Приладожья (ЮВ Фенноскандинавского щита) // Труды Ферсмановской научной сессии ГИ КНЦ РАН. 2020. № 17. С. 255-259.

4. Ладожская протерозойская структура (геология, глубинное строение и минерагения) (ред. Н. В. Шаров). Петрозаводск. Изд-во: КарНЦ РАН. 2020. 435 с.

5. Лобач-Жученко С.Б., Чекулаев В.П., Байкова В.С. Эпохи и типы гранитообразования в докембрии Балтийского щита. Л. Изд-во: Наука. 1974. 207 с.

6. Саранчина Г.М. Петрология Вялимякской интрузии и связанное с нею рудопроявление // Изв. КарелоФинск. науч.-исслед. базы АН СССР. 1948. № 2. С. 32-42.

7. Bohrson W.A., Spera F.J., Ghiorso M.S., Brown G.A., Creamer J.B., Mayfield A. Thermodynamic model for energy-constrained open-system evolution of crustal magma bodies undergoing simultaneous recharge, assimilation and crystallization: the Magma Chamber Simulator // J. Petrol. 2014. 55. P. 1685-1717. https://doi. org/10.1093/petrology/egu036 
8. Ghiorso M.S., Gualda G.A.R. An H2O-CO2mixed fluid saturation model compatible with rhyolite-MELTS // Contrib. Mineral. Petrol. 2015. 169. P. 1-30. https://doi.org/10.1007/s00410-015-1141-8.

9. Gualda G.A.R., Ghiorso M.S., Lemons R.V., Carley T.L. Rhyolite-MELTS: A modified calibration of MELTS optimized for silica-rich, fluid-bearing magmatic systems // J. Petrol. 2012. 53. P. 875-890. https://doi.org/10.1093/petrology/egr080.

10. Irvine T.N., Baragar W.R.A. A guide to the chemical classification of the common volcanic rocks // Canadian Journal of Earth Sciences. 1971. 8. P. 523-548.

11. Middlemost E.A.K. Naming Materials in the Magma/Igneous Rock System // Earth-Science Reviews. 1994. 37. P. 215-244.DOI: 10.1016/0012-8252(94)90029-9 